\title{
Article title
}

Understanding the economics of abuse: an assessment of the economic abuse definition within the Domestic Abuse Bill

\section{Author name}

Dr Nicola Sharp-Jeffs

\section{Affiliations}

Emeritus Research Fellow, Child and Woman Abuse Studies Unit, London Metropolitan University, England; Visiting Senior Fellow in Social Policy, University of Suffolk, England.

\begin{abstract}
The term 'economic abuse' was first introduced into discourse when it was identified as a tactic used by perpetrators within the Duluth Power and Control Wheel. Yet it is only recently that researchers have turned their attention to defining and understanding it. This paper draws on a review of the global and UK specific academic research literature to assess the suitability of the definition of economic abuse put forward within the Westminster Government's Domestic Abuse Bill. It recommends that a) the term 'any behaviour' within the definition is understood to include controlling tactics which sit under the constructs of economic restriction, exploitation and/or sabotage b) the definition recognises perpetrators will also prevent a partner from using/maintaining goods or services and c) attention is given to the suggestion that single incidents of economic abuse would not fall under this definition. Whilst the focus of this paper is on Westminster policy in the UK, the case for 'naming' and defining economic abuse in statute has wider resonance, not least because it provides a framework within which to report on prevalence, hold perpetrators accountable and for services (statutory and voluntary) to respond.
\end{abstract}

\section{5 key words}

Economic abuse; financial abuse; intimate partner violence; coercive control; Domestic Abuse Bill.

\section{Word count}

3.570

\section{Key messages}

- This paper critically assesses the definition of economic abuse within the Westminster Government's Domestic Abuse Bill and argues that there is 'room for improvement'.

- The term 'any behaviour' within the definition of economic abuse should be understood to include controlling tactics which sit under the constructs of economic restriction, exploitation and/or sabotage.

- A clear understanding of the constructs of economic abuse is vital if the Westminster Government is to report on prevalence (as required by the 
Istanbul Convention) and frontline practitioners are to understand and meet the complex needs of victim-survivors.

\section{Introduction}

Domestic abuse is a pattern of behaviour through which one partner exerts power and control over the other (Pence and Paymar, 1993) diminishing their 'space for action' (Kelly, 2003). The introduction of the criminal offence of controlling or coercive behaviour in an intimate or family relationship recognised this when it was introduced via section 76 of the Serious Crime Act (2015). It provided a legislative framework through which to recognise and respond to:

- Controlling behaviour - defined as a range of acts designed to make a person subordinate and/or dependent by isolating them from sources of support, exploiting their resources and capacities for personal gain, depriving them of the means needed for independence, resistance and escape and regulating their everyday behaviour; and

- Coercive behaviour - defined as a continuing act or pattern of acts of assault, threats, humiliation and intimidation or other abuse, which is used to harm, punish of frighten their victim (Home Office, 2015: 3).

Recognition that exploitation of a victim's resources can deprive them of the means needed for 'independence, resistance and escape' captures what Dutton and Goodman (2005: 749) describe as 'wearing down resistance' to coercive control through 'resource depletion'. Resources may be personal (such as physical stamina and determination), social (such as emotional support) and tangible/economic (such as transportation and a place to stay).

Yet, whilst it was widely recognised that the new offence of controlling or coercive behaviour provided a framework through which to understand and address emotional abuse, there was no recognition that it would also address economic abuse (Sharp \& Learmonth, 2017).

\section{Recognising economic abuse as a 'mechanism' of control}

Economic abuse has been described as 'probably the least researched area of partner violence, with very little academic literature on the topic' (Westmarland, 2015: 40). In a recent study which reviewed and analysed the global literature on economic abuse to determine how it is defined and what measures are used to capture its prevalence and impact, just 46 peer-reviewed articles (with a full or partial quantitative focus) were identified. The researchers observed that this was 'considerably small in comparison to the number of articles that would likely be identified in a global review focused on physical or sexual violence' (Postmus, et al., 2018: 277).

Until recently economic abuse has been conceptualised as a form of emotional abuse (Loring 1994), often subsumed into emotional or psychological abuse scales or subscales (Postmus, Plummer and Stylianou, 2016). This resulted in a 
lack of definitional clarity which makes it difficult to measure whether policy and practice responses are dealing appropriately with economic abuse.

Since the aim of this policy paper is to assess the suitability of the definition of economic abuse within the Westminster government's Domestic Abuse Bill, it is necessary to understand the debates in the research literature.

\section{Financial or economic abuse?}

The terms economic abuse and financial abuse are frequently used interchangeably (Sharp-Jeffs, 2015a). Postmus et al (2018) suggest that further clarity is needed as to whether they are the same phenomenon and indeed interchangeable or if, as Sharp-Jeffs (2015a) argues they are different, but related concepts. The distinction she makes is that financial abuse is part of economic abuse and involves similar behaviours; however financial abuse focuses specifically on money and finances and not economic resources more broadly including, for example, transportation and a place to stay. Christy et al., (2020: 3) reflect this distinction arguing economic abuse is the 'more inclusive' concept.

Controlling behaviours that limit women's economic well-being have been described within the violence against women literature since the 1970 . The vast majority of what Adams et al. (2019) describe as the 'common targets of control' are linked specifically to money and finances, including debt and damage to credit ratings. Additional forms identified within the 46 peer-reviewed articles analysed by Postmus et al. (2018: 266-276) include:

- Monitoring the use of/strictly limiting access to household resources

- Misusing family resources

- Damaging/destroying/stealing/pawning property or land

- Stopping a partner from using the telephone/internet/family car

- Turning off utilities

- Throwing a partner out of the house/evicting them from home/claiming home/car is theirs

- Depriving a partner of basic needs (food, shelter).

Just $14(30 \%)$ of the 46 articles they analysed were found to provide a clear economic abuse definition.

The term was first used in the late 1980 s to describe the tactics used by abusers within the Duluth Power and Control Wheel, but it was not defined in the research literature until 2008 when Adams and colleagues set out that:

'Economic abuse involves behaviours that control a person's ability to acquire, use, or maintain economic resources, thus threatening their economic security and potential for self-sufficiency' (Adams et al. 2008: 564). 
In the same article, the 'Scale of Economic Abuse' (SEA) is presented - the first attempt at measuring the phenomenon. Drawing on the literature and conversations with researchers, advocates and survivors, Adams and colleagues generated an initial pool of 120 items. This was refined to a 28 -item scale through data from a sample of 103 service-users (99\% experienced economic abuse), organised into two statistically distinct constructs: economic control (17 items) and economic exploitation (11 items).

In 2016, Postmus, Plummer and Stylianou tested the SEA with 120 women participating in a financial literacy program for survivors of domestic violence ( $94 \%$ experienced economic abuse) and using factor analysis produced a cut down scale of 12-items (SEA-12). They also added employment sabotage to the constructs of economic control and economic exploitation.

Postmus et al. (2018) show that most of the articles containing a clear definition draw either on the work of Adams et al. (2008) or Postmus et al. (2016): economic control was recognised in $87 \%(n=40)$, economic exploitation by $70 \%(n=32)$ and employment sabotage by $46 \%(n=21)$.

Adams and colleagues revisited both the SEA and SEA-12 scales, concluding that they failed to sufficiently reflect the 'function of economic abuse as a mechanism of control' (Adams et al. 2019: 269). Both the original and revised scales imply that control applies to a subset of economically abusive behaviours when, in fact, control underlies all economically abusive behaviour. Following the same iterative conceptual and statistical process, the researchers drew on data from 248 women seeking services ( $96 \%$ experienced economic abuse) to create a 14item scale which reflects a two-dimensional conceptualisation of control: economic restriction and economic exploitation.

- Economic restriction is described as limiting access to and use of economic resources, thereby forcibly establishing an arrangement in which the victim is dependent on the abuser for financial and material resources. Tactics include limiting access to income, denying access to bank accounts and financial information and imposing limits on the use of property.

- Economic exploitation is described as establishing an arrangement in which the victim's economic resources are used for the abuser's benefit, diminishing what the victim has built up and compromising their economic well-being - reversing the direction of dependence. Tactics include 'freeloading'1 (demanding that the victim solely pay for household necessities, buy them goods or pay their bills); stealing the victim's money/property; or generating debt in the victim's name through fraud and/or coercion. 
This development of the instruments used to measure economic abuse reflects the emerging scholarship within which the concept continues to be redefined and expanded (Anitha, 2019; Chowbey, 2017; Postmus et al. 2018). Studies to date have focused largely on women in heterosexual relationships who are Englishspeaking, with much located in the USA. Both Postmus et al. (2018) and Adams et al. (2019) recognise that research is needed with a wider demographic sample, exploring factors such as sexuality, age and ethnicity. Postmus et al. (2018) also suggest that more could be learned from the qualitative studies, conceptual articles and grey literature that fell outside of the scope of their study.

\section{The UK research literature on economic abuse}

Just three articles focusing on economic abuse in the UK have been published in peer-reviewed journals (Anitha, 2019; Chowbey, 2017; Christy et al. 2020) alongside two research reports (Sharp, 2008; Sharp-Jeffs, 2015a).

Chowbey (2017) notes that few studies have focused on economic abuse in the context of migration and for minoritised ethnic groups. She recruited 84 women for in-depth interviews from community settings. Thirty-five women were first and second generation British Pakistani Muslims $(n=23)$ and British Gujarati Hindus $(n=12)$ and 49 were Gujarati Hindus in India $(n=26)$ and Pakistani Muslims in Pakistan $(n=23$ ). More than one-third reported experiencing economic abuse $(n=33)$ and, of these, approximately two-thirds also reported physical abuse.

Chowbey (2017) drew on a categorisation of economic abuse which combined the work of Adams et al. (2008) and Sharp (2008). ${ }^{2}$ However, in Sharp's analysis, the construct of employment sabotage (identified by Postmus et al. 2016) is broadened out to economic sabotage. This is where the abuser creates additional costs which absorb available income, for example, disconnecting utilities and destroying their partner's belongings and/or household resources.

Women's narratives revealed forms of economic abuse that echo those already documented. Chowbey (2017) also identified what she describes as two 'unique' abuses. The first involved 'exploiting women's marriage gifts' - for example, threatening to throw them out of the house if they did not bring more dowry in the form of cash or household goods. Husbands and sometimes mothers-in-law also took control of gold (jewellery) for their own use. The second was 'jeopardising' women's long-term finances. In the British context, one of the most common forms of this was husbands making transnational investments for themselves and their parents and siblings. Money, including for essential household expenses, was used for building properties 'back home'.

Anitha (2019) also identified the surreptitious or coercive sale of women's dowry (jewellery or other assets) in her study which drew on life-history interviews with 41 South Asian women in transnational marriages in the UK and India. Yet, whilst 
Chowbey (2017) extended the four categories of economic abuse to six. Anitha (2019) instead framed the 'particularities' she observed within Postmus et al.'s (2016) three categories of economic control, economic exploitation and employment sabotage. For instance, control over bank accounts was also likely to be in the name of the male head of the household, often the father-in-law. Similarly, the theft of jewellery or other assets which were part of women's dowries, was classified as a culturally specific form of economic exploitation. Exploitation was also seen in the taking away of customary gifts given to the victim.

Anitha (2019) does, however, argue for broadening economic abuse to encompass women's reproductive labour - those tasks, responsibilities and roles such as cooking, cleaning and caring which are examples of economic activity, but which are not constructed in the same way as paid work. She observes that, through highlighting coercive control in the context of women's performance of their traditional gender roles such as housework and childcare, Stark (2007) drew 'welcome attention' to this realm, but that it has subsequently been neglected (Anitha, 2019: 1855). Exploitation of domestic labour is, of course, a shared experience for many women, yet it was common for South Asian women in the UK to be forced not only into serving the needs of their husbands and the in-laws with whom they lived, but also other relatives and their households.

Sharp (2008) also argues for a broader understanding which recognises 'institutional economic abuse' through: financial systems which facilitate the control of the abuser i.e. joint financial products which can only be closed with the consent of both parties; the governmental realm via aspects of the immigration and welfare benefits systems which create financial dependence on the abuser; and the criminal justice system, through the police discouraging a victim from making a formal report of domestic abuse when she is financially dependent on the abuser, or by refusing to provide a police escort to safely collect a victim's belongings if she leaves.

Some of these behaviours are linked to economic abuse post-separation. Whilst there is limited academic literature on this, it is consistent with Stark's (2007) observation that economic abuse is a form of 'structural' abuse which does not depend on physical proximity. Sharp-Jeffs, Kelly and Klein (2018) observed this when reporting two scales measuring coercive control and space for action. The space for action scale documented women's ability to restore agency and freedom in contexts of relative safety post separation. Whilst in some domains (individual, social, and community) freedom was enhanced over time, ongoing control and limiting women's economic assets post-separation was a direct interference in their efforts to rebuild their lives: one in five women reported economic abuse post-separation, including through interference in their employment and damage to property. 
Through the 'economic abuse' power and control wheel, Sharp (2008) illustrates how economic abuse overlaps with and reinforces other tactics of power and control. This makes it difficult to disentangle the specific impacts of economic abuse (Macdonald, 2012). However, Sharp-Jeffs (2015a) suggests the consequences can broadly be grouped as: women's financial well-being; psychological health; and physical health. Economic abuse is associated with: reduced economic self-sufficiency; increased financial strain; increased material hardship; debt and reduced access to financial resources (Adams et al. 2008; Littwin, 2012); increased depression, anxiety and reduced quality of life (Adams and Beeble, 2018; Postmus, Huang and Mathisen-Stylianou, 2012); and increased physical abuse and risk of homicide (Outlaw, 2009; Walby, 2004; Websdale, 1999).

In their interviews with service users and providers of domestic abuse services in England, Christy et al. (2020: 21) conclude that 'significant changes to policy' are needed so that service providers, policy makers and law enforcement do not 'continue to miss the mark' when it comes to 'remediating economic abuse' (ibid:1). They note that the Domestic Abuse Bill provides an opportunity to address this oversight through 'specifically and clearly' outlining the range of behaviours that fall under economic abuse (ibid: 3 ).

\section{Economic Abuse and the Domestic Abuse Bill}

The Domestic Abuse Bill, aimed specifically at England and Wales, started its passage through the Westminster Parliament in June 2017, was consulted on between March and May 2018, and was published in draft form in January 2019. It was introduced into Parliament in July 2019 but fell in October 2019 with the announcement of the UK general election. The Bill had already faced parliamentary delays following the prorogation of the UK Parliament in August 2019 which was later declared unlawful. At the time of writing, the Bill had been reintroduced to Parliament in March 2020 and reached second reading in the House of Lords.

Until this point, work to address violence against women and girls in England and Wales had followed various policy definitions, all of which referenced 'financial abuse' (see, for example Home Office, 2013). However, in the consultation response published alongside the Bill, the Westminster Government stated that it would 'specify economic abuse as a distinct type of abuse, as it encompasses a wider range of behaviours than financial abuse' (HM Government, 2019: 7). This is consistent with the argument put forward by Sharp-Jeffs (2015a).

The wording of the economic abuse definition within the Bill reflects this broader understanding, by referring to money or 'other property' as well as 'goods or services' (House of Commons, 2020a).

\section{Current definition of economic abuse}


1(4) "Economic abuse" means any behaviour that has a substantial adverse effect on B's ability to -

(a) Acquire, use or maintain money or other property, or

(b) Obtain goods or services.

The commentary on the provisions found in the Explanatory Notes to the Bill further expand on these terms: 'property' is understood to cover items such as a mobile phone or a car, whilst 'goods and services' cover, for example, utilities such as heating, or items such as food and clothing (House of Commons, 2020b). In the narrative on how economic abuse 'goes beyond' financial abuse, the report accompanying the draft Bill refers to additional 'targets of control' (Adams et al. 2019), including housing, credit ratings and the criminal and family court systems (HM Government, 2019).

The Government definition clearly draws on the academic definition of economic abuse put forward by Adams et al. (2008) by linking it to the victim's ability to 'acquire, use or maintain' economic resources in (a). It is unclear why (b) also refers to the ability to 'obtain' goods and services, since to obtain an economic resource could be interpreted in the same way as 'acquiring' it. Similarly, the literature review is clear that abusers may also prevent their partner from using or maintaining goods or services i.e. stopping a partner from using the internet, disconnecting utilities.

At the same time, the definition does not explicitly recognise the 'function of economic abuse as a mechanism of control' through the restriction and exploitation constructs that Adams et al. (2019) argue must be captured. Whilst the definition of 'abusive' behaviour within the Bill at clause 1(3) does set out that it includes controlling or coercive behaviour (c), it also goes on to state that it does not matter whether the behaviour consists of a single incident or a course of conduct' (House of Commons, 2020a: 1). Yet this is inconsistent with the Explanatory Notes to the Bill in relation to economic abuse which state:

'The purpose of including the qualification "substantial and adverse effect" is to ensure that isolated incidents, such as damaging someone's car, or not disclosing financial information, are not inadvertently captured.' (House of Commons, 2020b: 16)

A clear understanding of the constructs of economic abuse is vital if the Westminster Government is to report on prevalence. The Istanbul Convention requires State Parties to provide disaggregated data on all forms of violence covered by the scope of the Convention (Walby, 2016). Although the Crime Survey for England and Wales measures financial abuse, the Office for National Statistics (ONS) presents the findings under the heading 'non-physical' forms of domestic abuse, alongside the answer to a question on emotional abuse. As well as being reported on separately, the question on financial abuse needs to be revised. Not only is it subjective, asking participants whether an intimate partner 
has prevented them from having a 'fair share' of the household money, but it does not capture the multi-faceted nature of economic abuse (Sharp-Jeffs, 2015b).

A shared understanding of these constructs is also important for frontline practitioners if they are to understand and meet the complex needs of victimsurvivors. Abusers both draw on existing gendered economic inequality and dependence or create economic instability through restriction and/or exploitation. This means that women across all socio-economic groups can experience economic abuse. The UK-based research on the experiences of South Asian women shows that whilst intersectional inequalities may mean that the tactics of economic abuse are varied, they still sit within the overarching 'function of economic abuse as a mechanism of control' falling under restriction and/or exploitation. This recognition is important since it may prevent practitioners from 'othering' women from different socio-economic and ethnic backgrounds through culturalising their experiences (see Thiara and Gill, 2010).

Future research could, however, explore whether economic sabotage (Sharp, 2008) should sit alongside economic restriction and economic exploitation (Adams et al. 2019). Whilst employment sabotage (Postmus et al. 2016) can be seen to fall under restriction i.e. stopping a partner from acquiring an income, the sabotage of economic resources which must be replaced does not sit comfortably within either this construct or the construct of exploitation. This makes the demonstrable impact on the ability of women to maintain economic resources invisible.

Similarly, the suggestion that economic exploitation 'reverses the direction of dependence' (Adams et al. 2019) should be re-examined since the research literature also contains examples of abusers using this tactic in a way that enables them to maintain and grow their own economic resources.

\section{Conclusion}

At each stage of the Bill's development, women's groups have supported the inclusion of economic abuse within the statutory definition of domestic abuse (HM Government 2019).3 The Bill has provided a welcome opportunity to 'rediscover' the term economic abuse, which recognises the scope and complexity of the controlling tactics involved. Recent research (Adams et al., 2008; Adams et al. 2019; Postmus et al., 2016; Sharp, 2008; Sharp et al. 2018) has made clear that it requires a distinct response, both through policy and in practice.

This paper has critically assessed the definition of economic abuse within the Domestic Abuse Bill. Whilst the definition draws on established academic understandings, there is room for improvement. Specific reference to 'any behaviour' as including control through restriction, exploitation and/or sabotage is required by adding a clause or an Explanatory Note. 
Subsections (a) and (b) of clause 1(4) should also be merged (see below) so that there is recognition that perpetrators may also prevent a partner from using or maintaining goods or services.

\section{Proposed revised definition of economic abuse}

1(4) "Economic abuse" means any behaviour (economic restriction, exploitation and/or sabotage) that has a substantial adverse effect on B's ability to acquire, use or maintain money or other property, goods or services.

Whilst the focus of this paper has been on legal and policy developments in England and Wales, the case for 'naming' economic abuse in statute has wider resonance, not least because it provides a framework within which to hold perpetrators accountable and for services (statutory and voluntary) to respond.

The Author declares that there is no conflict of interest.

Thank you to Professor Liz Kelly (London Metropolitan University) and Cyrene Siriwardhana (Legal \& Policy Advisor, Surviving Economic Abuse) for their comments on early drafts. 


\section{References}

Adams, A. and Beeble, M. (2018) 'Intimate Partner Violence and Psychological Well-Being: Examining the Effect of Economic Abuse on Women's Quality of Life' Psychology of Violence. 9(10): 517-525.

Adams, A., Sullivan, C., Bybee, D. and Greeson, M., (2008) 'Development of the Scale of Economic Abuse' Violence Against Women, 14(5): 563-587.

Adams, A., Greeson, M., Littwin, A. and Javorka, M. (2019) 'The Revised Scale of Economic Abuse (SEA2): Development and Initial Psychometric Testing of an Updated Measure of Economic Abuse in Intimate Relationships' Psychology of Violence 10(3): 268-278.

Anitha, S., (2019) 'Understanding Economic Abuse Through an Intersectional Lens: Financial Abuse, Control, and Exploitation of Women's Productive and Reproductive Labor' Violence Against Women, 25(15): 1854-1877.

Chowbey, P., (2017) 'Women's narratives of economic abuse and financial strategies in Britain and South Asia' Psychology of Violence, 7(3): 459-468.

Christy, K., Welter, T., Dundon, K. and Bruce, A. (2020) Economic abuse: a subtle but common form of power and control, Journal of Interpersonal Violence, 9/10 (35): $1-27$.

Dutton, M. A. and Goodman, L. (2005) 'Coercion in Intimate Partner Violence: Toward a New Conceptualization' Sex Roles 52(11/12): 743-755.

Home Office (2015) Coercive or controlling behaviour in an intimate or family relationship: statutory guidance framework.

https://assets.publishing.service.gov.uk/government/uploads/system/upload s/attachment_data/file/482528/Controlling_or_coercive_behaviour__statutory_guidance.pdf

Home Office (2013) Information for local areas on the change to the definition of domestic violence and abuse.

https://assets.publishing.service.gov.uk/government/uploads/system/upload s/attachment_data/file/142701/guide-on-definition-of-dv.pdf

House of Commons (2020a) Domestic Abuse Bill. https://publications.parliament.uk/pa/bills/cbill/58-01/0096/20096.pdf

House of Commons (2020b) Domestic Abuse Bill: Explanatory Notes. https://publications.parliament.uk/pa/bills/cbill/5801/0096/en/20096en.pdf 
HM Government (2019) Transforming the Response to Domestic Abuse: consultation response and draft bill.

https://assets.publishing.service.gov.uk/government/uploads/system/upload s/attachment_data/file/772202/CCS1218158068-Web_Accessible.pdf

Kelly, L. (2003) The wrong debate: reflections on why force is not the key issue with respect to trafficking in women for sexual exploitation, Feminist Review, 73(1): 139-44.

Littwin, Angela K. (2012) Coerced Debt: The Role of Consumer Credit in Domestic Violence (June 1, 2012). California Law Review, 100(4): 952-1020

Loring, M. T. (1994). Emotional Abuse. New York: Lexington Books.

Macdonald, F. (2012) Spotlight on Economic Abuse: A Literature and Policy Review. Australia: Good Shepherd and Wyndham Legal Service.

Outlaw, M. (2009) 'No One Type of Intimate Partner Abuse: Exploring Physical and Non-Physical Abuse Among Intimate Partners' Journal of Family Violence. 24: 263-27.

Outlaw, M. (2009) No one type of intimate partner abuse: exploring physical and non-physical abuse among intimate partners, Journal of Family Violence, 24(4): 263-27.

Pence, E., and Paymar, M. (1993) Education groups for men who batter. New York: Springer.

Postmus, J., Plummer, S. and Stylianou, A., (2016) 'Measuring Economic Abuse in the Lives of Survivors: Revising the Scale of Economic Abuse' Violence Against Women, 22(6): 692-703.

Postmus, J., Huang, C. and Mathisen-Stylianou, A. (2012) The impact of physical and economic abuse on maternal mental health and parenting. Children and Youth Services Review, 34(9): 1922-28.

Postmus, J., Hoge, G., Breckenridge, J. Sharp-Jeffs, N. and Chung, D. (2018) 'Economic Abuse as an Invisible Form of Domestic Violence: A Multi-country Review'. Trauma, Violence and Abuse 21(2): 261-283

Sharp, N. (2008) 'What's Yours is Mine' The different forms of economic abuse and its impact on women and children experiencing domestic violence. Refuge 
Sharp-Jeffs, N., Kelly, L. \& Klein, R. (2018) Long Journeys Toward Freedom: The Relationship Between Coercive Control and Space for Action-Measurement and Emerging Evidence Violence against Women 24(2):163-185.

Sharp-Jeffs, N. (2015a) A Review of Research and Policy on Financial Abuse within Intimate Partner Relationships London: CWASU

Sharp-Jeffs, N. (2015b) Money Matters: Research into the Extent and Nature of Financial Abuse within Intimate Relationships in the UKLondon: The Co-operative Bank/Refuge

Sharp-Jeffs, N. with Learmonth, S. (2017) Into plain sight: how economic abuse is reflected in successful prosecutions of controlling or coercive behaviour. London: Surviving Economic Abuse.

Stark, E. (2007) Coercive Control: How Men Entrap Women in Personal Life. Oxford: Oxford University Press.

Thiara, R. and Gill, A. (2010) Violence Against Women in South Asian Communities: Issues for Policy and Practice London: Jessica Kingsley.

Walby, S. (2016) Ensuring data collection and research: A collection of papers on the Council of Europe Convention on preventing and combating violence against women and domestic violence.

Walby, S. \& Allen, J (2004) Domestic Violence, Sexual Assault and Stalking: Findings from the British Crime Survey, London: Home Office Research Study 276.

Websdale, N. (1999) Understanding Domestic Homicide California: North-Eastern University Press.

Westmarland, N. (2015). Violence against Women. Criminological perspectives on men's violences. Routledge.

\footnotetext{
${ }^{1}$ Sharp (2008) refers to this as 'refusing to contribute'

${ }^{2}$ Based on a sample of 55 women accessing a domestic abuse service (89\% experienced economic abuse), Sharp (2008) identified four 'types' of economic abuse: interfering with education/employment; controlling access to economic resources; refusing to contribute; and generating economic costs

${ }^{3}$ Led by the charity Surviving Economic Abuse:

https://www.theguardian.com/commentisfree/2018/mar/14/economic-abuse-crimepoverty-suffered-domestic-violence
} 
